\title{
Assessment of the choice of malaria diagnostic methods among household heads of the Nkwen village in Bamenda-3 municipality
}

\section{NFOR Omarine Nlinwe (PhD)}

Department of Medical Laboratory Science, Faculty of Health Sciences, The University of Bamenda, Bambili, N.W. Region of Cameroon

E-mail; omarinenlinwe@yahoo.ca,

Tel. +237-670222093

\begin{abstract}
Malaria remains a major threat to life in Bamenda in particular and Cameroon in general. Despite numerous and relatively affordable malaria diagnostic and treatment methods, accurate choice of diagnosis remains a major challenge to the inhabitants of the almost 14,285 households in the Nkwen village of the Bamenda 3 municipality. This study was designed to investigate the key determinants of the choice of malaria diagnostic methods (demand side analysis) in the Nkwen village of the Bamenda 3 municipality. A purposive and randomized sampling method was employed to recruit of 560 household's heads from the 46 quarters of the Nkwen village. The Multinomial Logistic Regression Model and Chi-Square analysis were used to analyze the collected data. The findings reveal that gender, marital status, educational level, income, household size, age, religion and health insurance policy contribute to the choice of malaria diagnostic methods in the study area. Therefore, the integration of socio-economic factors into malaria control policies will feasibly contribute to malaria decrease in the study area.
\end{abstract}

Key Words: Malaria; Malaria Diagnosis, Health Care Services, Multinomial Logistic Model.

Received: $21 / 08 / 2020$

Accepted: $13 / 10 / 2020$

DOI: https//dx.doi.org/10.4314/jcas.v16i2.2

(C) The Authors. This work is published under the Creative Commons Attribution 4.0 International Licence. 


\section{Introduction}

Malaria remains a global health problem especially in the WHO African Region. According to the most recent World malaria report, there were 228 million cases of malaria in 2018 compared to 231 million cases in 2017, resulting to an estimated 405000 and 416000 malaria deaths in 2018 and 2017 respectively (Nlinwe and Ateh 2020). Prompt malaria diagnosis constitutes a key element in malaria control strategy because it results in reduced complications and deaths from malaria (Oo et al. 2019). When malaria is properly diagnosed, nonmalaria febrile illnesses will be accurately treated guided by test results (Shillcutt et al. 2008). In fact, it was estimated that approximately 100,000 lives can be possibly save in a year, if malaria is accurately diagnosed (Hawkes and Kain 2007). The initial signs and symptoms of malaria which are variable and generally not well defined includes headache, abdominal pain, weakness, fever, vomiting, diarrhea, dizziness, myalgia, nausea and chills (Tangpukdee et al. 2009). Despite these obvious signs and symptoms, malaria confirmatory laboratory diagnosis remain an immediate need because clinical diagnosis alone (physical examinations, signs and symptoms), can be highly interrupted by infections with other tropical diseases (Tangpukdee et al. 2009). Rather than giving presumptive treatment, the WHO advised that only established malaria cases be treated, so as to effectively fight malaria (Ruizendaal et al. 2014). Although patients may sometimes be enthusiastic about being tested for malaria before treatment (Chandler et al. 2008; Bamiselu et al. 2016), other factors were found to delay early seeking for appropriate malaria diagnosis and treatment; level of education, socio-economic status of the family, type of marriage/marital status, age and parity (Chukwuocha et al. 2014). Therefore this study was designed to investigate the determinants of the choice and association of types of malaria diagnostic methods in the Bamenda health area of Cameroon.

\section{Materials and Methods}

This study was carried out in Nkwen, one of the two villages of Bamenda 3 municipality. Nkwen village has about 14,285 households with 46 quarters (Mbanga 2018). In each quarter $5 \%$ of the total households were randomly selected giving an estimated number of 714 targeted households. A total of 560 targeted household heads actually participated in the study giving a compliance rate of $78.43 \%$. The Bamenda 3 municipality is one of the three municipalities in Bamenda, which are all administratively covered by the Bamenda city council. Bamenda is the chief town of the North West region of Cameroon. Cameroon has ten regions. The study period was for seven months, from October 2018 to May 2019.

Data were analyzed with the use of descriptive statistics (Tables and Charts) and the Multinomial Logistic regression Model (MLM). The Multinomial Logistic Regression Model relies on the fundamental assumption that the error term in estimating $\tau_{i j}$ is independent of the error term in estimating $\tau_{i k}$. This implies that the error term in estimating the choice probability of individual $i$ alternative $j$ is independent of the error term in estimating the choice probability of individual for alternative $k(k \neq j)$. To model the choice of malaria diagnostic methods, three diagnostic choices were used in the study: diagnosis by signs and symptoms, clinical examination and laboratory examination (Williams 2006; Kakkilaya 2003; Murray et al. 2008). These variables were treated as nominal scale categories so that the effect should be gotten across the individual categories. To see how this can be done, let $Y i j$ $=1$, if the individual chooses alternative $(j=1$ or 2$)$ $=3$, otherwise (since 3 is the base category) Further, let $\tau_{i j}=\operatorname{Pr}(Y i j=1)$ where $\operatorname{Pr}$ stands for probability. Therefore, $\tau_{i 1}, \tau_{i 2}, \tau_{i 3}$ represent the probabilities that individual $i$ chooses alternative 1,2 , or 3 , respectively - that is alternatives of diagnosis by signs and symptoms, diagnosis by clinical examination, and diagnosis by laboratory examination. If these are the only alternatives an 
individual faces, then, obviously, $\tau_{i 1}+\tau_{i 2}+\tau_{i 3}=1$

This is because the sum of the probabilities of mutually exclusive and exhaustive events must be 1. $\tau s$ will be called response probabilities. This means that in our example, if we determine any two probabilities, the third one is determined automatically. In other words, there is no need to estimate the three probabilities independently. Now, what are the factors or variables that determine the probability of choosing a particular option? In the choice of malaria diagnosis model, information on the variables includes: Gender of respondent $(\mathrm{GEN})=1$ if male, 0 otherwise; Marital status of respondent (MS) $=1$ if married, 0 otherwise; Educational level of respondent $(\mathrm{EDU})=1$ if no education, 2 if primary, 3 if secondary, 4 if university undergraduate 5 if university post graduate; Income of respondent $(Y)=$ less than 30,000(1) 31,000-50,000(2) 51,000-100,000(3)101,000-150,000(4), 151,000$250,000(5), \quad 251,000-350,000(6), 351,000-$ $500,000(7)$, above 500,000(8); Number of people living in each household (NLH) $=1$ for $0-3,2$ for 4-6, 3 for 7-9 and 4 for 10+; Age of respondent $(\mathrm{Ag})=1$ if Less than 20years, 2 if 21-40years, 3 if 41-60years, and 4 if above 61years; Place of residence $(\mathrm{PoR})=1$ for urban, 0 otherwise; Religion of respondent $(\operatorname{ReG})=1$ for Christian, 0 otherwise; Health insurance policy $(\mathrm{HIP})=1$ insured, 0 otherwise; Cost of diagnosis $(\mathrm{C})=$ less than or equal to $1000(1), 1,00-2000(2), 2001$ 3000(3), 3001-4000(4), Above 4000(5) (3).

Generalizing the bivariate logistic regression model, we can write the multinomial logit model (MLM) as:

$$
\tau_{i j}=\frac{e^{\alpha_{j}+\beta_{j} X_{i}}}{\sum_{j=1}^{3} e^{\alpha_{j}+\beta_{j} X_{i}}}
$$

Where $X i$ represent the explanatory variables. Notice that we have put the subscript $j$ on the intercept and the slope coefficients to remind us that the values of these coefficients can differ from choice to choice. In other words, the three probabilities estimated may have different coefficients for the regressors. In effect, we are estimating three regressions. As we noted before, we cannot estimate all the three probabilities independently. The common practice in MLM is to choose one category or choice as the base, reference or comparison category and set its coefficient values to zero. So if we choose the third category (laboratory test) and set $\alpha_{1}=0$ and $\beta_{1}=0$ we obtain the estimates of the probabilities for the two other choices. We then find out the impact of a unit change in the value of a regressor on the choice probability, holding all other regressors values constant. That is, we find out $\frac{\partial \tau_{i j}}{\partial X_{i k}} \quad$ which is the partial derivative of $\tau_{i j}$ with respect to the $\mathrm{k}^{\text {th }}$ explanatory variable. This is known as the marginal effect interpretation which is adopted in this paper.

\section{Results}

The findings presented on table 4.1 represents the summary of descriptive statistics. The results justify the homogeneity of the findings. 
REVUE DE L'ACADEMIE DES SCIENCES DU CAMEROUN Vol. 16 No. 2 (Sept 2020)

Table 1: Summary of Descriptive Statistics

\begin{tabular}{|c|c|c|c|c|c|c|c|c|c|c|c|c|}
\hline & MDM & Gen & MS & EDU & $\mathbf{Y}$ & NLH & Ag & PoR & ReG & GenHH & HIP & C \\
\hline Mean & 1.288 & .456 & .364 & .948 & 2.476 & 2.32 & 1.98 & .248 & .956 & .696 & .104 & 2.772 \\
\hline Std. Dev. & .864 & .498 & .482 & .222 & 1.999 & .944 & .603 & .432 & .205 & .460 & .306 & 1.089 \\
\hline Maximum & 2 & 1 & 1 & 1 & 8 & 4 & 4 & 1 & 1 & 1 & 1 & 5 \\
\hline Minimum & 0 & 0 & 0 & 0 & 1 & 1 & 1 & 0 & 0 & 0 & 0 & 1 \\
\hline Skewness & -.590 & .177 & .565 & -4.036 & 1.084 & .440 & .665 & 1.167 & -4.446 & -.852 & 2.595 & .330 \\
\hline Kurtosis & 1.599 & 1.031 & 1.319 & 17.285 & 2.939 & 2.317 & 5.013 & 2.362 & 20.773 & 1.726 & 7.731 & 2.776 \\
\hline Observations & 560 & 560 & 560 & 560 & 560 & 560 & 560 & 560 & 560 & 500 & 560 & 560 \\
\hline
\end{tabular}

The findings presented on table 4.2 represents pairwise correlation matrix results. The results show that the correlation coefficients for the leading diagonals is 1.0000 , with the rest less than 1 . This indicates that each variable is perfectly collinear to itself and therefore justifies the reliability of the results because no variable is strongly correlated with the other, except with itself.

Table 2: Correlation Matrix Table

\begin{tabular}{|c|c|c|c|c|c|c|c|c|c|c|c|c|}
\hline & MDM & Gen & MS & EDU & $\mathbf{Y}$ & NLH & $\mathrm{Ag}$ & PoR & ReG & GenHH & HIP & C \\
\hline MDM & 1.0000 & & & & & & & & & & & \\
\hline Gen & 0.0155 & 1.0000 & & & & & & & & & & \\
\hline MS & 0.1665 & 0.0501 & 1.0000 & & & & & & & & & \\
\hline EDU & -0.0367 & -0.1473 & 0.0649 & 1.0000 & & & & & & & & \\
\hline $\mathbf{Y}$ & -0.0563 & 0.2323 & 0.2569 & -0.0164 & 1.0000 & & & & & & & \\
\hline NLH & -0.0567 & 0.0811 & 0.0078 & 0.0222 & -0.1085 & 1.0000 & & & & & & \\
\hline Ag & 0.2954 & 0.0304 & 0.2733 & -0.0675 & 0.2438 & 0.0816 & 1.0000 & & & & & \\
\hline PoR & -0.0521 & -0.0980 & -0.0687 & -0.1158 & 0.1136 & 0.0801 & -0.0424 & 1.0000 & & & & \\
\hline ReG & 0.0264 & -0.0385 & 0.0812 & 0.4768 & -0.2517 & 0.0728 & -0.2012 & -0.2381 & 1.0000 & & & \\
\hline GenHH & -0.1119 & 0.1861 & 0.3373 & 0.0802 & -0.0167 & 0.0675 & -0.1517 & -0.1642 & 0.3246 & 1.0000 & & \\
\hline HIP & -0.1213 & -0.0225 & -0.0943 & 0.0798 & 0.1026 & -0.1573 & -0.1191 & 0.1381 & -0.2464 & -0.0027 & 1.0000 & \\
\hline C & -0.0451 & 0.1660 & -0.0325 & 0.0337 & 0.0684 & 0.1724 & 0.0357 & -0.1861 & 0.1881 & 0.0533 & -0.1333 & 1.0000 \\
\hline
\end{tabular}

Source: Compiled by Author Using Stata Version 12.0

The findings presented on table 4.3 are the Multinomial Logistic Regression Model (MLM) with robust standard errors to take care of the problem of heteroscedasticity. Comparing the choice between signs and symptoms with laboratory tests (base outcome), the coefficient of gender is negative showing that males are $16.11 \%$ less likely $(\mathrm{P}<0001)$ to prefer signs and symptoms over laboratory test for malaria diagnosis, compared to females. The males are also $16.08 \%$ more likely $(\mathrm{P}<0001)$ to prefer clinical diagnosis over laboratory test, as compared to females. The coefficient of marital status is negative for both results showing that marriage decreases the likelihood of preferring signs and symptoms by $13.04 \%$ in favor of laboratory test $(\mathrm{P}<0001)$. An increase in the level of education of a household head will decrease the likelihood for them to prefer signs and symptoms and clinical examination over laboratory test by 20.87\% ( $\mathrm{P}<0001)$ and $21.51 \%(\mathrm{P}<005)$, respectively. The results also show that an increase in income will decrease the likelihood $(\mathrm{P}<0001)$ to diagnose malaria using only signs and symptoms and clinical examination by $50.59 \%$ and $15.86 \%$ respectively. 
An increase in the number of people living in each household will increase the likelihood $(\mathrm{P}<0001)$ to diagnose malaria through signs and symptoms and clinical examination over laboratory test, by $75.15 \%$ and $71.24 \%$ respectively. Increase in age will decrease $(\mathrm{P}<0001)$ the likelihood to diagnose malaria via signs and symptoms only, in favor of laboratory test by $28.64 \%$. Christians are $32.73 \%$ less likely ( $\mathrm{P}<$ 005) to prefer signs and symptoms over laboratory examination, as compared to non-Christians. People who are covered by health insurance policy are $8.17 \%$ less likely $(\mathrm{P}<005)$ to prefer clinical diagnosis in favor of laboratory examination. The results are generally 99 percent reliable for policy prescriptions.

Table 3: Multinomial Logistic Regression Results with laboratory tests as the base outcome

\begin{tabular}{|c|c|c|c|c|c|}
\hline & Signs and Symptoms & & Clinical Diagnosis & & \\
\hline Variable & $\begin{array}{l}\text { Coefficient } \\
\text { (Robust Std. Err) }\end{array}$ & $\begin{array}{l}\text { Marginal Effects } \\
\text { (Robust Std. Err) }\end{array}$ & $\begin{array}{l}\text { Coefficient } \\
\text { (Robust Std. Err) }\end{array}$ & $\begin{array}{l}\text { Marginal Effects } \\
\text { (Robust Std. Err) }\end{array}$ & \\
\hline Gen & $\begin{array}{l}-.7776957 * * * \\
(.2633367)\end{array}$ & $\begin{array}{l}-.1610894^{* * *} \\
(.04079)\end{array}$ & $\begin{array}{l}1.000014 * * * \\
(.3148446)\end{array}$ & $\begin{array}{l}.160812^{* * *} \\
(.03749)\end{array}$ & \\
\hline MS & $\begin{array}{l}-.9192191 * * * \\
(.2986136)\end{array}$ & $\begin{array}{l}-.1303514^{* * *} \\
(.04322)\end{array}$ & $\begin{array}{l}-.5287262^{*} \\
(.2924936)\end{array}$ & $\begin{array}{l}-.038744 \\
(.034)\end{array}$ & \\
\hline EDU & $\begin{array}{l}2.100195^{*} \\
(1.103174)\end{array}$ & $\begin{array}{l}.208705^{* * *} \\
(.04002)\end{array}$ & $\begin{array}{l}-.9277837^{*} \\
(.4855517)\end{array}$ & $\begin{array}{l}-.2151145^{* *} \\
(.10759)\end{array}$ & \\
\hline $\mathbf{Y}$ & $\begin{array}{l}.2885841 * * * \\
(.0699367)\end{array}$ & $\begin{array}{l}.0505966^{* * *} \\
(.01158)\end{array}$ & $\begin{array}{l}-.0486472 \\
(.0762922)\end{array}$ & $\begin{array}{l}-.0158626 \\
(.00968)\end{array}$ & \\
\hline NLH & $\begin{array}{l}.3529664 * * * \\
(.1248397)\end{array}$ & $\begin{array}{l}.0751457 * * * \\
(.0206)\end{array}$ & $\begin{array}{l}-.4597349 * * \\
(.1835441)\end{array}$ & $\begin{array}{l}-.0712405^{* * *} \\
(.02097)\end{array}$ & \\
\hline Ag & $\begin{array}{l}-1.683849 * * * \\
(.2467968)\end{array}$ & $\begin{array}{l}-.2864079 * * * \\
(.04136)\end{array}$ & $\begin{array}{l}.0177631 \\
(.2550349)\end{array}$ & $\begin{array}{l}.0580925^{*} \\
(.03022)\end{array}$ & \\
\hline PoR & $\begin{array}{l}-.3417252 \\
(.3786267)\end{array}$ & $\begin{array}{l}-.091848^{*} \\
(.04954)\end{array}$ & $\begin{array}{l}1.046623 * * * \\
(.2951627)\end{array}$ & $\begin{array}{l}.1764048^{* * *} \\
(.0512)\end{array}$ & \\
\hline ReG & $\begin{array}{l}-1.475669 * * \\
(.6886361)\end{array}$ & $\begin{array}{l}-.3272787^{* *} \\
(.16401)\end{array}$ & $\begin{array}{l}.0374301 \\
(.7008586)\end{array}$ & $\begin{array}{l}.0666862 \\
(.06006)\end{array}$ & \\
\hline GenHH & $\begin{array}{l}.8485977 * * * \\
(.2932226)\end{array}$ & $\begin{array}{l}.1108907 * * * \\
(.04012)\end{array}$ & $\begin{array}{l}.7787873^{* *} \\
(.3136899)\end{array}$ & $\begin{array}{l}.0694558^{* *} \\
(.03384)\end{array}$ & \\
\hline HIP & $\begin{array}{l}.4575331 \\
(.3390314)\end{array}$ & $\begin{array}{l}.1068053 \\
(.06532)\end{array}$ & $\begin{array}{l}-.6519105 \\
(.5110818)\end{array}$ & $\begin{array}{l}-.081711^{* *} \\
(.04037)\end{array}$ & \\
\hline C & $\begin{array}{l}.1726773 \\
(.1300878)\end{array}$ & $\begin{array}{l}.0303605 \\
(.02206)\end{array}$ & $\begin{array}{l}-.0316888 \\
(.1582284)\end{array}$ & $\begin{array}{l}-.0098258 \\
(.02021)\end{array}$ & \\
\hline Constant & $\begin{array}{l}-.6876589 \\
(1.134485)\end{array}$ & - & $\begin{array}{l}-.7566995 \\
(1.022544)\end{array}$ & - & \\
\hline Number of obs & & & & & 500 \\
\hline Wald chi2(24) & & & & & 150.82 \\
\hline Prob $>$ chi 2 & & & & & 0.0000 \\
\hline Pseudo R2 & & & & & 0.5689 \\
\hline
\end{tabular}

Source: Compiled by Author Using Stata Version 12.0 Note: *(**) $\left(^{* * *}\right)=>$ The null hypothesis is rejected at $10 \%(5 \%)(1 \%)$ level of significance Note: Laboratory Test $=>$ Based Category.

The results presented on table 4.4 shows that the value of the Pearson Chi-Square stands at 5.816, which is greater than its asymptotic value and significant at 10 percent level of significance. Therefore malaria diagnostic method is likely (coefficient of the likelihood ratio; $6.079(\mathrm{P}<0.005)$ ) associated with its prevalence, with a linear-by-linear association between the two variables. 
Table 4: Chi-Square Tests of Association between Malaria Diagnostic Method and Malaria Prevalence

\begin{tabular}{|c|c|c|c|}
\hline \multicolumn{4}{|l|}{ Chi-Square Tests } \\
\hline & Value & Df & Asymp. Sig. (2-sided) \\
\hline Pearson Chi-Square & $5.816 \mathrm{a}$ & 2 & .055 \\
\hline Likelihood Ratio & 6.079 & 2 & .048 \\
\hline Linear-by-Linear & 4.715 & 1 & .030 \\
\hline \multicolumn{4}{|l|}{ Association } \\
\hline $\mathbf{N}$ of Valid Cases & 484 & & \\
\hline
\end{tabular}

Source: Compiled by Author Using SPSS Version 20.0

From the findings presented on table 4.5 above, the coefficients of Cramer's V, Contingency and Phi stands at .610, .709 and .610 respectively, significant at 10 percent level of statistical significance. All coefficients are greater than 0.50 , indicating that there is a strong 90 percent confident association between malaria diagnostic method and the prevalence of malaria. The coefficients for Pearson's R, and Spearman Correlation stand at .599 and .503 respectively. The coefficients are significant at the 5 percent level of significance. There is therefore a strong relationship between malaria diagnostic method and the prevalence of malaria.

Table 5: Symmetric Measures of Association between Malaria Diagnostic Method and Malaria Prevalence

\begin{tabular}{|c|c|c|c|c|c|}
\hline \multicolumn{6}{|l|}{ Symmetric } \\
\hline & Value & Asymp. Std. Errora & Approx. Tb & Approx. Sig. & \\
\hline \multirow{5}{*}{$\begin{array}{l}\text { Nominal } \\
\text { Nominal }\end{array}$} & Phi & .610 & & & .055 \\
\hline & & & & & \\
\hline & Cramer's V & .610 & & & .055 \\
\hline & Contingency & .709 & & & .055 \\
\hline & Coefficient & & & & \\
\hline \multirow{3}{*}{$\begin{array}{l}\text { Interval by Interval } \\
\text { Ordinal by Ordinal }\end{array}$} & Pearson's R & .599 & .041 & 2.180 & $.030 \mathrm{c}$ \\
\hline & Spearman & .503 & .042 & 2.271 & $.024 \mathrm{c}$ \\
\hline & Correlation & & & & \\
\hline $\mathbf{N}$ of Valid Cases & 484 & & & & \\
\hline
\end{tabular}

Source: Compiled by Author Using SPSS Version 20.0

\section{Discussion}

According to the above findings, household heads in the following categories were significantly prone to malaria diagnosis using laboratory tests (RDT/microcopy): Males; decrease house hold size; Christian; insured; married, older, increase educational level and increase income. In line with findings from (Yaya et al. 2017), malaria prevention practices among women is low. In order to improve the attitude towards proper malaria diagnosis, rigorous behavioral communication involvement of especially young female household heads is encouraged. Since being single and young also predisposes the household heads to inaccurate malaria diagnostic methods. Increase in educational level and increase knowledge should be encouraged by the provision of free/subsidized education. Education creates awareness, hence increasing the likelihood to comply with recommended practice of accurate malaria diagnosis and control in general (Munisi et al. 2019). Family planning and reduction in family size could possibly control malaria by improving the standard of living in households. Reduce household size will reduce the cost on healthcare, hence encouraging compliance to best practice of malaria laboratory diagnosis. In line with previous findings, improvement in the standard of living in households significantly impacts malaria control (Sharma et al. 2015).

Therefore, socio economic measures aimed at encouraging gender equality, promoting education, encouragement of family planning should be fostered. Furthermore, poverty reduction strategies such as encouragement of entrepreneurial activities that will increase income levels, in addition to reduction in the cost of malaria diagnosis are all strongly recommended. Encouragement of more people to under-take 
health insurance policy will also ensure accurate malaria diagnosis. In conclusion, to effectively improve on the outcome of malaria control efforts in the study area, the integration of these socioeconomic factors is highly recommended.

\section{Acknowledgements}

Appreciation goes to Njimanted Godfrey Forgha, Yakum Ivan Mboambogoh and Fozoh Isiah Aziseh, for participating in the data collection and analysis exercises.

\section{References}

Bamiselu OF, Ajayi I, Fawole O, Dairo D, Ajumobi O, Oladimeji A, Steven Y (2016) Adherence to malaria diagnosis and treatment guidelines among healthcare workers in Ogun State, Nigeria. BMC Public Health 16 (1):828

Chandler CI, Mwangi R, Mbakilwa H, Olomi R, Whitty CJ, Reyburn H (2008) Malaria overdiagnosis: is patient pressure the problem? Health policy and planning 23 (3):170-178

Chukwuocha UM, Okpanma AC, Nwakwuo GC, Dozie INS (2014) Determinants of delay in seeking malaria treatment for children under-five years in parts of South Eastern Nigeria. Journal of community health 39 (6):1171-1178

Hawkes M, Kain KC (2007) Advances in malaria diagnosis. Expert review of anti-infective therapy 5 (3):485-495

Kakkilaya BS (2003) Rapid diagnosis of malaria. Laboratory medicine 34 (8):602-608

Mbanga LA (2018) Human Settlement Dynamics in the Bamenda III Municipality, North West Region, Cameroon. Journal of Settlements and Spatial Planning 9 (1):47-58

Munisi DZ, Nyundo AA, Mpondo BC (2019) Knowledge, attitude and practice towards malaria among symptomatic patients attending Tumbi Referral Hospital: A cross-sectional study. PloS one 14 (8)

Murray CK, Gasser RA, Magill AJ, Miller RS (2008) Update on rapid diagnostic testing for malaria. Clinical microbiology reviews 21 (1):97110

Nlinwe NO, Ateh TAE (2020) Assessment of Malaria Predisposing Factors among Crop Production Farmers Attending the Ndop District Hospital, Northwest Region of Cameroon. Journal of Parasitology Research 2020

Oo WH, Gold L, Moore K, Agius PA, Fowkes FJ (2019) The impact of community-delivered models of malaria control and elimination: A systematic review. Malaria journal 18 (1):269

Ruizendaal E, Dierickx S, Grietens KP, Schallig HD, Pagnoni F, Mens PF (2014) Success or failure of critical steps in community case management of malaria with rapid diagnostic tests: a systematic review. Malaria journal 13 (1):229

Sharma RK, Singh MP, Saha KB, Bharti PK, Jain V, Singh P, Silawat N, Patel R, Hussain M, Chand S (2015) Socio-economic \& household risk factors of malaria in tribal areas of Madhya Pradesh, central India. The Indian journal of medical research 141 (5):567

Shillcutt S, Morel C, Goodman C, Coleman P, Bell D, Whitty CJ, Mills A (2008) Cost-effectiveness of malaria diagnostic methods in sub-Saharan Africa in an era of combination therapy. Bulletin of the World Health Organization 86:101-110

Tangpukdee N, Duangdee C, Wilairatana P, Krudsood S (2009) Malaria diagnosis: a brief review. The Korean journal of parasitology 47 (2):93

Williams R (2006) Review of regression models for categorical dependent variables using Stata, by Long and Freese. The Stata Journal 6 (2):273278

Yaya S, Bishwajit G, Ekholuenetale M, Shah V, Kadio B, Udenigwe O (2017) Knowledge of prevention, cause, symptom and practices of malaria among women in Burkina Faso. PLoS One 12 (7):e0180508 